\title{
Análise da Resistência à Corrosão por Pite em Soldas de Reparo pelo Processo TIG em Aço Inoxidável Superduplex UNS S32750
}

\author{
(Analysis of Pitting Corrosion Resistance in Welding Repair by GTAW Procedure in a Superduplex Stainless Steel UNS \\ S32750)
}

\author{
Juliana Primo Basílio de Souza ${ }^{1}$, Alexandre de Gouvêa Arias², Juan Manuel Pardal', Fernando Benedicto Mainier ${ }^{3}$, Miguel Luiz. \\ Ribeiro Ferreira², Sérgio Souto Maior Tavares ${ }^{1}$. \\ ${ }^{1}$ Universidade Federal Fluminense, Programa de Pós-Graduação em Engenharia Mecânica - PGMEC, Niterói, RJ, Brasil. \\ (juanpardal@vm.uff.br) \\ ${ }^{2}$ Universidade Federal Fluminense, Departamento de Engenharia Mecânica, Niterói, RJ, Brasil. \\ ${ }^{3}$ Universidade Federal Fluminense, Departamento de Engenharia Química, Niterói, RJ, Brasil.
}

\begin{abstract}
Resumo
Atualmente, os aços inoxidáveis superduplex (AISD) estão sendo muito empregados no Brasil em setores industriais tais como petroquímico, energético, naval e plataformas offshore, tendo vasta aplicação em vasos de

pressão em processos críticos, trocadores de calor, reatores, tubulações, umbilicais, digestores, bombas e naqueles componentes onde a produtividade contínua é essencial e o custo não é a maior limitação. No entanto, durante processos de fabricação e montagem, assim como na vida em serviço destes componentes de processo pode existir a necessidade eventual de efetuar soldagens de reparo. Deste modo, o presente trabalho, visa avaliar a microestrutura e os valores de resistência à corrosão por pites na zona termicamente afetada (ZTA) e metal de solda do AISD UNS S32750 durante a simulação de um processo de reparo mediante a utilização do processo de soldagem TIG $(G T A W)$. Os resultados obtidos permitem estabelecer diretrizes para a realização de procedimentos de soldagem de reparo em AISD.
\end{abstract}

Palavras-chave: Aço Inoxidável Superduplex; Soldagem de reparo TIG; Resistência à corrosão.

Abstract: Currently superduplex stainless steels (SDSS) are being extensively employed in the petrochemical, power generation, naval and offshore industries. The uses of these materials are: pressure vessels for critical processes, heat exchangers, reactors, pipes, umbilicals, digesters, pumps and other facilities where continuous use is essential and cost is not the main limitation. However, during fabrication and assembly, or as consequence of service, repair welding operations may be necessary. Thus, in this study a simulation of welding repair by GTAW process was performed in a SDSS UNS S32750. The objective of this work was to evaluate the microstructure and the values of critical pitting resistance (CPT) in the weld metal, heat affected zone and base metal. The results obtained allows the determination of welding procedures and recommendations useful to the welding repair of SDSS.

Key-words: Superduplex Stainless Steel; GTAW repair process; Corrosion resistance.

\section{Introdução}

O crescente avanço das atividades de exploração e produção de petróleo offshore e o aumento da produtividade em meios mais agressivos alavancaram a procura por materiais que possuam elevadas propriedades mecânicas, assim como uma excelente resistência à corrosão em contato com estes meios. No amplo campo dos aços inoxidáveis existentes, as ligas de aço inoxidável superduplex (AISD) se destacaram por aliar estas propriedades, sendo também procuradas por outros segmentos industriais [1].

Os aços inoxidáveis duplex (AID) e superduplex (AISD) são materiais que aliam uma alta resistência à corrosão com

(Recebido em 01/11/2010; Texto final em 16/05/2011).

Artigo originalmente publicado no COBEF 2010 valores elevados de resistência mecânica produto dos diversos elementos de liga contidos em solução sólida na liga, além da fina microestrutura bifásica composta por proporções semelhantes das fases ferrita (d) e austenita (g) [2]. Porém, é interessante salientar que estes aços podem sofrer fenômenos de fragilização e perda de resistência à corrosão provocados pelo aquecimento localizado, tal como acontece em diversos processos de soldagem. A maioria dessas transformações está relacionada à ferrita (d), pois a taxa de difusão nesta fase é aproximadamente 100 vezes mais rápida do que na austenita $(\mathrm{g})$ [3]. Neste contexto, a fase sigma (s) é um dos compostos que se precipita e mais prejudica as propriedades dos AISD [4-5]. Esta fase deletéria, rica em Cr, é fortemente fragilizante e pode se formar entre $650^{\circ} \mathrm{C}$ e $1000^{\circ} \mathrm{C}$ [3], mas este intervalo é fortemente dependente da composição química da liga [6]. Esta fase, freqüentemente é associada a uma forte redução na tenacidade ao impacto e à perda de resistência à corrosão da liga. Neste sentido, a precipitação de $4 \%$ em volume de fase s pode resultar em um decréscimo de aproximadamente 
$90 \%$ da tenacidade [7].

Neste contexto, a soldagem dos AID e AISD é uma operação que exige grandes cuidados, pois esta família de aços inoxidáveis se solidifica com uma microestrutura $100 \%$ ferrítica e a austenita somente surge por difusão no resfriamento abaixo de $1250-1300^{\circ} \mathrm{C}$. Deste modo, uma velocidade de resfriamento muito rápida conduz a uma microestrutura com maior proporção de ferrita e rica em nitretos de cromo $\left(\mathrm{Cr}_{2} \mathrm{~N}\right)$. Por outro lado, um resfriamento muito lento pode provocar principalmente, a formação da fase intermetálica $\sigma$ a partir da fase ferrita (d) [3, 7]. Deste modo, estas duas formas de desbalanço microestrutural devem ser evitadas na soldagem de AID e AISD. As medidas para evitar estas mudanças microestruturais indesejáveis são a utilização de metal de adição mais rico em $\mathrm{Ni}$, uso de gás de proteção com adição de 1 a 3\% nitrogênio na soldagem TIG e controle do aporte de calor para que não seja muito baixo. Para se evitar a precipitação de intermetálicos, a principal medida é o controle do aporte de calor, para que não seja excessivamente alto. Recomenda-se aporte de calor entre $0,5 \mathrm{~kJ} / \mathrm{mm}$ e $2,5 \mathrm{~kJ} / \mathrm{mm}$ para a soldagem de AID e entre $0,2 \mathrm{~kJ} / \mathrm{mm}$ e $1,5 \mathrm{~kJ} / \mathrm{mm}$ para os
AISD [8]. Neste contexto, é recomendado para AISD um tempo de resfriamento de, no máximo, 120 segundos no intervalo crítico de formação de fases deletérias entre $950^{\circ} \mathrm{C} \mathrm{e} 700^{\circ} \mathrm{C}$ [9].

No entanto, em muitas situações práticas pode ser necessária a realização de uma soldagem de reparo por alguma falha do material em serviço ou pela presença de defeitos durante a fabricação. Apesar disso, os procedimentos de reparo para AID e AISD ainda são pouco difundidos. Neste trabalho, a partir da simulação de uma soldagem de reparo pelo processo TIG $(G T A W)$ em aço inoxidável superduplex UNS S32750 foram avaliadas as características microestruturais do metal de solda (MS), zona termicamente afetada (ZTA) em comparação com o metal de base (MB). No entanto, existe um grande interesse no mercado que, após de executada a soldagem de reparo, se mantenham os valores de resistência à corrosão do MB na ZTA e MS. Deste modo, ensaios para determinação da temperatura crítica de pites (CPT) foram também realizados em diversas regiões da solda com o intuito de verificar a influência dos parâmetros e condições soldagem de reparo na resistência à corrosão por pites.

Tabela 1. Intervalo de composição química de cada elemento do AISD UNS S32750.

\begin{tabular}{|c|c|c|c|c|c|c|c|c|}
\hline \multicolumn{10}{|c|}{ Composição química (\% em peso) } \\
\hline $\mathrm{Cr}$ & $\mathrm{Ni}$ & $\mathrm{Mo}$ & $\mathrm{Mn}$ & $\mathrm{C}$ & $\mathrm{S}$ & $\mathrm{P}$ & $\mathrm{Si}$ & $\mathrm{N}$ \\
\hline $24,0-26,0$ & $6,0-8,0$ & $3,0-5,0$ & 1,0 & 0,03 & 0,02 & 0,035 & 0,80 & $0,24-0,32$ \\
\hline
\end{tabular}

Tabela 2. Composição química do metal de adição.

\begin{tabular}{|c|c|c|c|c|c|c|c|c|c|}
\hline \multicolumn{10}{|c|}{ Composição química (\% em peso) } \\
\hline $\mathrm{Cr}$ & $\mathrm{Ni}$ & $\mathrm{Mo}$ & $\mathrm{Mn}$ & $\mathrm{C}$ & $\mathrm{S}$ & $\mathrm{P}$ & $\mathrm{Si}$ & $\mathrm{N}$ & $\mathrm{Cu}$ \\
\hline 25,05 & 9,03 & 3,62 & 0,82 & 0,021 & 0,001 & 0,025 & 0,32 & 0,244 & 0,54 \\
\hline
\end{tabular}

Tabela 3. Tipo de tecimento do cordão e temperatura de pré-aquecimento.

\begin{tabular}{|c|c|c|}
\hline $\mathrm{cp}$ & Tipo de tecimento do cordão & Temperatura de pré-aquecimento $\left({ }^{\circ} \mathrm{C}\right)$ \\
\hline 1 & Retilíneo & 20 \\
\hline 2 & Oscilante & 20 \\
\hline 3 & Retilíneo & 400 \\
\hline 4 & Oscilante & 400 \\
\hline
\end{tabular}

Tabela 4. Parâmetros de soldagem e informações levantadas em cada corpo-de-prova (cp).

\begin{tabular}{|c|c|c|c|c|}
\hline cp & 1 & 2 & 3 & 4 \\
\hline Tensão $(\mathrm{V})$ & 11,2 & 11,8 & 12,4 & 12,8 \\
\hline Corrente $(\mathrm{A})$ & 116 & 116 & 112 & 112 \\
\hline Comprimento $(\mathrm{mm})$ & 118 & 118 & 118 & 118 \\
\hline Tempo $(\mathrm{s})$ & 28 & 157 & 41 & 1,0 \\
\hline $\mathrm{vs}(\mathrm{mm} / \mathrm{s})$ & 4,2 & 0,8 & 2,9 & 0,723 \\
\hline $\mathrm{H}(\mathrm{kJ} / \mathrm{mm})$ & 0,154 & 0,911 & 0,241 & 0,6 (Chapa Fina) \\
\hline Parâmetro $\tau$ & $1,8($ Chapa Grossa) & 0,7 (Chapa Fina) & 1,1 (Chapa Grossa) & 138 \\
\hline $\mathrm{T}_{\mathrm{T} 2 / \mathrm{T} 1}(\mathrm{~s})$ & 0,65 & 28 & 1,01 & \\
\hline
\end{tabular}




\section{Materiais e Métodos}

\subsection{Material Estudado}

Foi utilizado um segmento de tubulação de aproximadamente 12,7 mm de espessura de AISD UNS S32750. A tabela 1 mostra o intervalo de composição química de cada elemento no metal base. O metal de adição empregado no processo foi a vareta TIG AWS 25.9.4.L cuja composição química é mostrada na tabela 2. Este consumível possui composição química semelhante à do metal de base, mas é enriquecido com $9 \%$ de níquel para estabilizar a formação de austenita e promover o equilíbrio entre as fases.

\subsection{Procedimento de Reparo}

Foram realizadas quatro simulações de soldagem de reparo, mediante único passe, pelo processo manual TIG em corpos-deprova (cps) de dimensões de 118 x $51 \mathrm{~mm}$ retirados do segmento de tubulação. A tabela 3 mostra o tipo de tecimento do cordão e a temperatura de pré-aquecimento nos materiais estudados, enquanto que na tabela 4 são apresentados os parâmetros de soldagem em cada corpo-de-prova (cp).

Todas as simulações do processo de reparo foram efetuadas com corrente contínua e polaridade direta (CC-) empregando argônio puro como gás de proteção. Para garantir com mais confiabilidade uma proporção satisfatória de austenita $(\mathrm{g})$ no metal de solda, uma das recomendações para soldagem de AISD é a utilização de misturas gasosas contendo 1 a $3 \%$ de nitrogênio. Entretanto, por serem misturas mais caras e muitas vezes não estarem disponíveis quando realizados reparos emergenciais, optou-se por utilizar argônio puro $(99,99 \%)$ como gás de proteção, com vazão de 12 litros por minuto.

A equação (1) representa a estimativa do aporte de calor durante o processo de reparo, cujos valores para cada amostra são informados na tabela 4 . Na tabela 4, são também apresentados os tempos de resfriamento entre $950^{\circ} \mathrm{C}$ e $750^{\circ} \mathrm{C}$ dos cordões depositados. O cálculo do tempo de resfriamento, neste intervalo de temperatura, foi efetuado mediante uso das equações (6) e (7), fazendo uso das constantes apresentadas na tabela 5 [10].

$$
H=\eta \frac{V . I}{v_{s}}
$$

Onde:

$\mathrm{H}=$ Aporte de Calor $(\mathrm{kJ} / \mathrm{mm})$

$\mathrm{h}=$ Eficiência do processo de soldagem $(0,5)$.

$\mathrm{I}=$ Intensidade de Corrente (A)

$\mathrm{V}=$ Tensão de Soldagem $(\mathrm{V})$

$\mathrm{v}_{\mathrm{s}}=$ Velocidade de Soldagem $(\mathrm{mm} / \mathrm{s})$

A equação (2) foi empregada na estimação do parâmetro adimensional $\tau$ determinando o tipo de chapa para utilização da equação apropriada do regime de resfriamento em cada amostra [11].

$\tau=e \sqrt{\frac{\rho C\left(T-T_{0}\right)}{H}}$
Onde:

$e-$ Espessura (mm)

$r$ - Massa específica $\left(\mathrm{g} / \mathrm{mm}^{3}\right)$

$C$ - Capacidade calorífica $\left(\mathrm{J} / \mathrm{g}^{\circ} \mathrm{C}\right)$

$\mathrm{T}$ - Temperatura de interesse $\left({ }^{\circ} \mathrm{C}\right)$

$\mathrm{T}_{0}$ - Temperatura de pré-aquecimento $\left({ }^{\circ} \mathrm{C}\right)$

$\mathrm{H}$ - Aporte de calor $(\mathrm{J} / \mathrm{mm})$

Se o parâmetro $\mathrm{t}$ for maior que 0,75 é considerado o regime de resfriamento para chapa grossa [11]. Assim sendo, são apresentadas as equações da velocidade de resfriamento correspondentes ao regime de chapa fina e grossa, respectivamente.

$v_{R}=2 \pi k \rho C\left(\frac{e}{H}\right)^{2}\left(T-T_{0}\right)^{3} \quad$ Chapa Fina

$v_{R}=\frac{2 \pi k\left(T-T_{0}\right)^{2}}{H} \quad$ Chapa Grossa

Desta forma, integrando-se as equações (3) e (4), conforme a equação (5), obtém-se, respectivamente, as equações do tempo de resfriamento $\left(t_{\mathrm{T} 2 / \mathrm{T} 1}\right)$ para chapas finas (6) e para chapas grossas (7) avaliando-se um intervalo de temperaturas $\left(\mathrm{T}_{2} / \mathrm{T}_{1}\right)$. Cabe ainda ressaltar que, para intervalo de temperatura de interesse estudado $\left(950^{\circ} \mathrm{C}-750^{\circ} \mathrm{C}\right)$, o valor de T adotado na equação (2) foi o valor médio de $825^{\circ} \mathrm{C}$.

$v_{R}=\frac{d T}{d t} \Leftrightarrow t=\int \frac{d T}{v_{R}}$

$t_{r z / Z 1} \approx \frac{H^{2}}{\pi k \rho C e^{2}}\left\{\frac{1}{\left(T_{1}-T_{0}\right)^{2}}-\frac{1}{\left(T_{2}-T_{0}\right)^{2}}\right\}$ Chapa Fina

$t_{r 2 \pi 1}=\frac{H}{2 \pi k}\left\{\frac{1}{\left(T_{1}-T_{60}\right)}-\frac{1}{\left(T_{2}-T_{0}\right)}\right\} \quad$ Chapa Grossa

Onde:

$\mathrm{k}$ - Condutividade térmica do metal $\left(\mathrm{J} / \mathrm{mm} \mathrm{s}{ }^{\circ} \mathrm{C}\right)$

$\mathrm{T}_{2}$ - Temperatura de interesse inicial $\left({ }^{\circ} \mathrm{C}\right)$

$\mathrm{T}_{1}$ - Temperatura de interesse final $\left({ }^{\circ} \mathrm{C}\right)$

Tabela 5. Propriedades físicas de alguns AID/AISD [10]

\begin{tabular}{|c|c|c|c|}
$\begin{array}{c}\text { Aço } \\
\text { Inoxidável }\end{array}$ & $\begin{array}{c}\text { Densidade } \\
\left(\mathrm{g} / \mathrm{mm}^{3}\right)\end{array}$ & $\begin{array}{c}\text { Condutividade } \\
\text { Térmica }(\mathrm{K}) \\
\left(\mathrm{J} / \mathrm{mm} \mathrm{s}{ }^{\circ} \mathrm{C}\right)\end{array}$ & $\begin{array}{c}\text { Capacidade } \\
\text { Calorífica }(\mathrm{C}) \\
\left(\mathrm{J} / \mathrm{g}^{\circ} \mathrm{C}\right)\end{array}$ \\
\cline { 1 - 1 } UNS S31803 & \multirow{2}{*}{0,0078} & 0,015 & 0,50 \\
\cline { 1 - 1 } UNS S32750 & \multirow{2}{*}{ UNS S32760 } & & \\
\cline { 1 - 1 }
\end{tabular}

\subsection{Caracterização da microestrutura e determinação da CPT}

Para análise da microestrutura foram extraídas duas amostras para cada cp de condição de soldagem, uma pertencente ao metal 


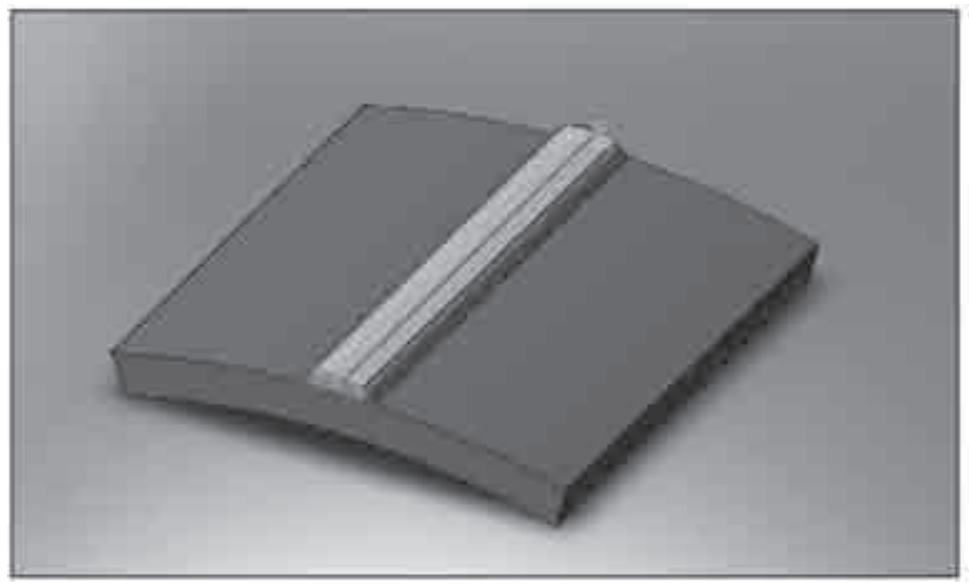

(a)

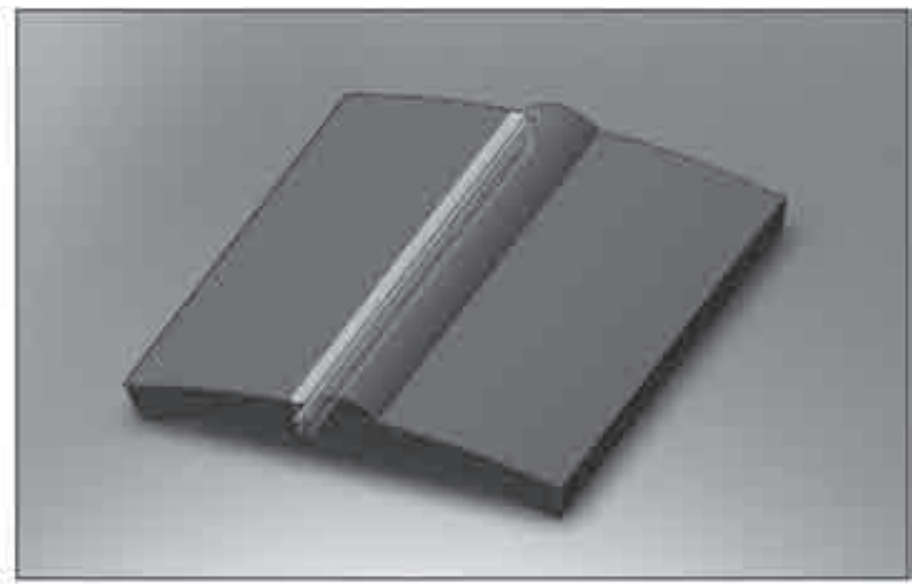

(b)

Figura 1. Esquema da seção utilizada, na cor amarela, para produção das amostras a partir dos cps produzidos: (a) Metal de solda (MS); (b) Zona termicamente afetada pelo calor (ZTA).

Tabela 6. Reagentes utilizados para revelar características microestruturais do AISD.

\begin{tabular}{|c|c|c|}
\hline Ataque & Composição & Objetivo \\
\hline Beraha & $\begin{array}{c}\text { Solução aquecida, composta de: } 20 \mathrm{ml} \mathrm{de} \mathrm{HCl} \mathrm{em} 100 \\
\text { ml } \mathrm{H}_{2} \mathrm{O} \text { destilada }+0,3 \mathrm{a} 0,6 \mathrm{~g} \text { de metabissulfito de } \\
\text { potássio. Temperatura do banho entre } 40 \mathrm{e} 80^{\circ} \mathrm{C} .\end{array}$ & $\begin{array}{c}\text { Revelar as fases ferrita }(\delta) \text { e austenita }(\gamma) \text { das } \\
\text { amostras solubilizadas [12]. Caracterizar as } \\
\text { mudanças microestruturais nas amostras. }\end{array}$ \\
\hline $\begin{array}{c}\text { Hidróxido de } \\
\text { Potássio (KOH) }\end{array}$ & $\begin{array}{c}15 \mathrm{~g} \text { de } \mathrm{KOH} \text { em } 100 \mathrm{ml} \mathrm{de} \mathrm{H}_{2} \mathrm{O} \text { destilada. Ataque } \\
\text { eletrolítico: Amostra no anodo, aplicação de 3 } \mathrm{V} \\
\text { durante } 12 \mathrm{~s} .\end{array}$ & $\begin{array}{c}\text { Caracterizar as mudanças microestruturais nas } \\
\text { amostras estudadas. }\end{array}$ \\
$\begin{array}{c}\text { Revelar fases deletérias }\left(\sigma, \chi, \gamma_{2}, \text { entre outras) nas }\right. \\
\text { amostras [13-14]. Efetuar análises macrográficas em } \\
\text { cps. }\end{array}$ \\
\hline
\end{tabular}

de solda (MS) e outra correspondente à zona termicamente afetada (ZTA), de acordo com o esquema apresentado nas figuras 1(a) e 1(b), respectivamente. Por fim, foi retirada também analisada uma amostra do metal de base (MB), para comparação.

$\mathrm{Na}$ caracterização por microscopia ótica (MO), as amostras foram lixadas seqüencialmente até lixa de granulometria $1200 \mathrm{e}$ a seguir polidas com pasta de alumina em suspensão aquosa de 1,0 e $0,1 \mu \mathrm{m}$, respectivamente. A caracterização das diferentes amostras foi efetuada mediante o emprego de distintos ataques metalograficos, descritos na tabela 6 .

As quantificações das fases ferrita (d) e austenita (g), assim como também das fases deletérias foram realizadas através do emprego do programa Image Tools v.3.0 [15]. Esta análise foi realizada tomando como média 20 imagens por condição de tratamento com diferentes aumentos metalográficos.

A estimativa do valor da CPT de cada condição ensaiada foi realizada com base nas recomendações da norma ASTM G15099 [16], utilizando um Potenciostato m Autolab® Type III. O ensaio foi efetuado com solução de $1 \mathrm{M} \mathrm{NaCl}$ em uma célula contendo 3 eletrodos como mostrado na figura 2, sem desaeração prévia. Além do eletrodo de trabalho, foi utilizado um eletrodo de calomelano saturado (SCE) como referência e uma folha de platina como contra-eletrodo.

A partir das amostras retiradas em cada cp foram confeccionados os eletrodos de trabalho através da fixação da amostra a um fio rígido de $\mathrm{Cu}$. Em seguida, estes eletrodos foram embutidos em resina de cura a frio. A superfície da cada amostra em contato com o eletrólito foi preparada até a lixa de granulometria 400. De modo a evitar corrosão por frestas, as laterais e vértices do eletrodo em contato com a resina foram recobertas com esmalte incolor.

Durante o ensaio, um potencial constante de $700 \mathrm{mV}$ foi aplicado no eletrodo de trabalho em relação ao eletrodo de referência (SCE). A célula eletroquímica foi aquecida em um banho-maria com taxa constante de $4^{\circ} \mathrm{C}$ por minuto a partir de uma temperatura inicial de $8^{\circ} \mathrm{C}$. $\mathrm{O}$ potenciostato registrava a corrente em função do tempo, enquanto os valores de temperatura em relação ao tempo foram adquiridos manualmente com um termômetro digital. Assim, a CPT é a temperatura pela qual a densidade de corrente (di) aumenta acima de $100 \mu \mathrm{A} / \mathrm{cm}^{2}$ mantendo-se acima deste valor crítico no mínimo por sessenta segundos [16], tal como apresentado na figura 3 para o eletrodo referente ao metal de solda do cp 1. 


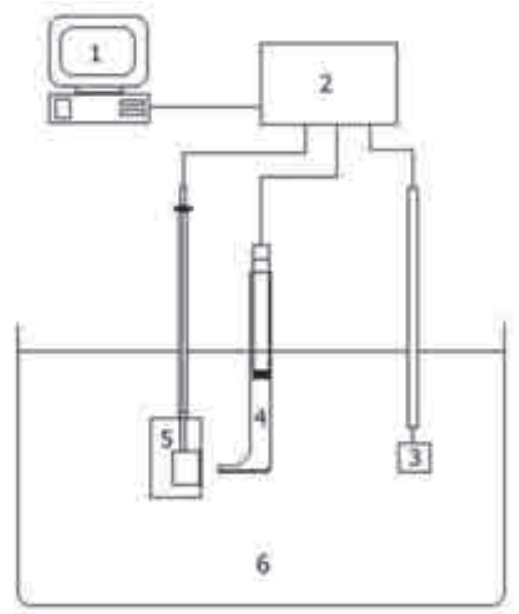

\section{Legenda}

1. Computador

2. Potencostato

3. Eletrodo de Platina

4. Capillar de Luggin

JEletrodo de Calomeiano Soturado

5. Elutrodo de Trabahtio

6. Becker com soluchio

Figura 2. Esquema de montagem da célula eletrolítica para determinação da temperatura crítica de pites (CPT).

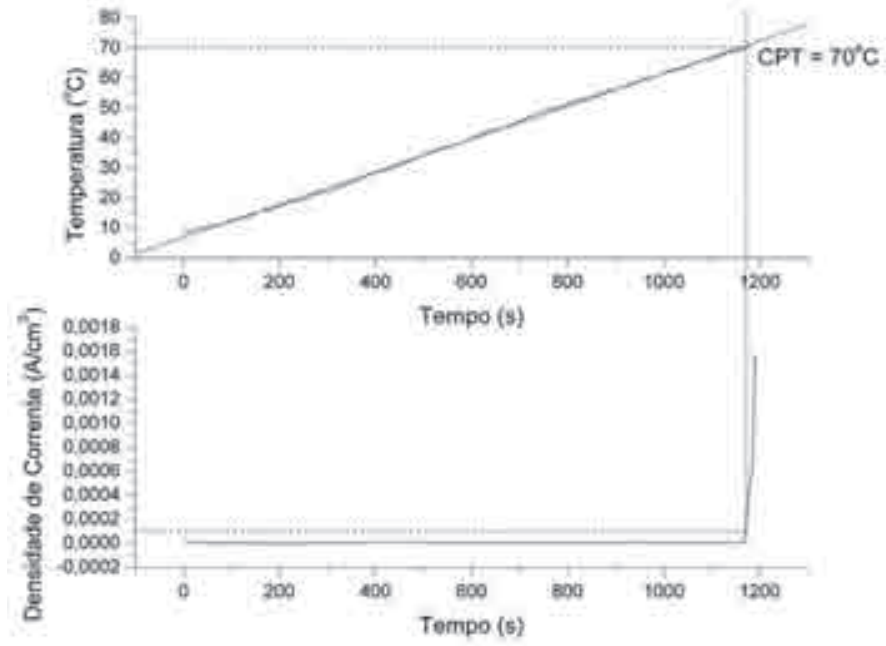

Figura 3. Gráficos levantados na determinação da temperatura critica de pites (CPT) no AISD soldado com passe retilíneo e sem pré-aquecimento (Cp 1).

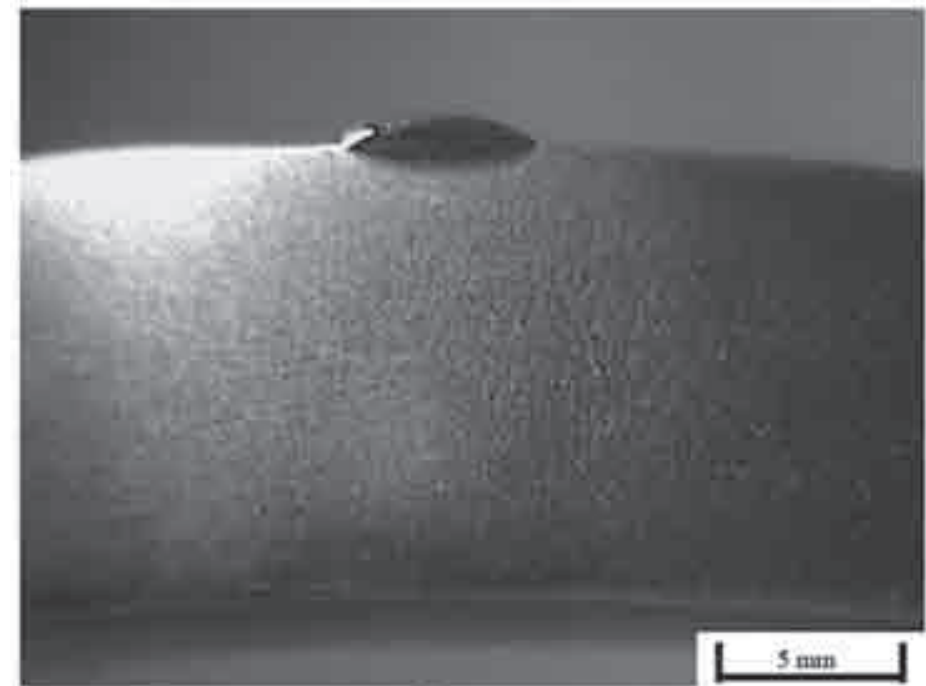

(a)

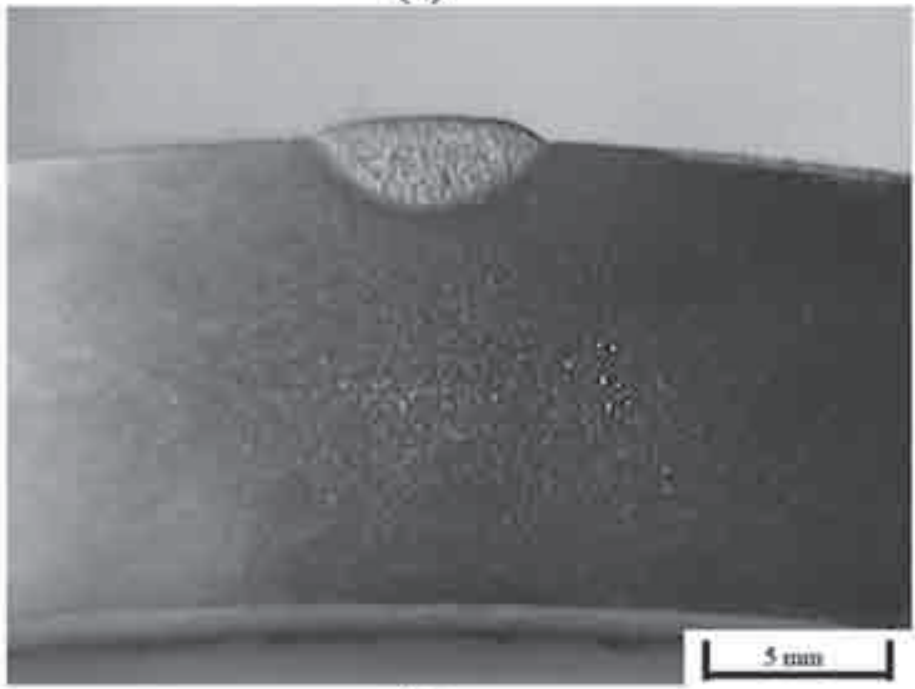

(c)

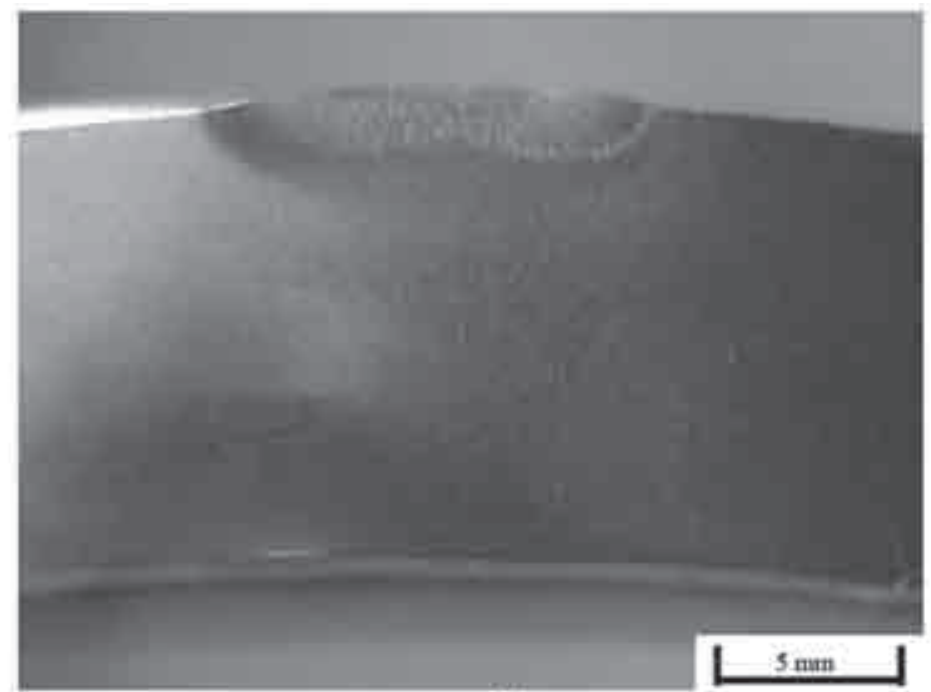

(b)

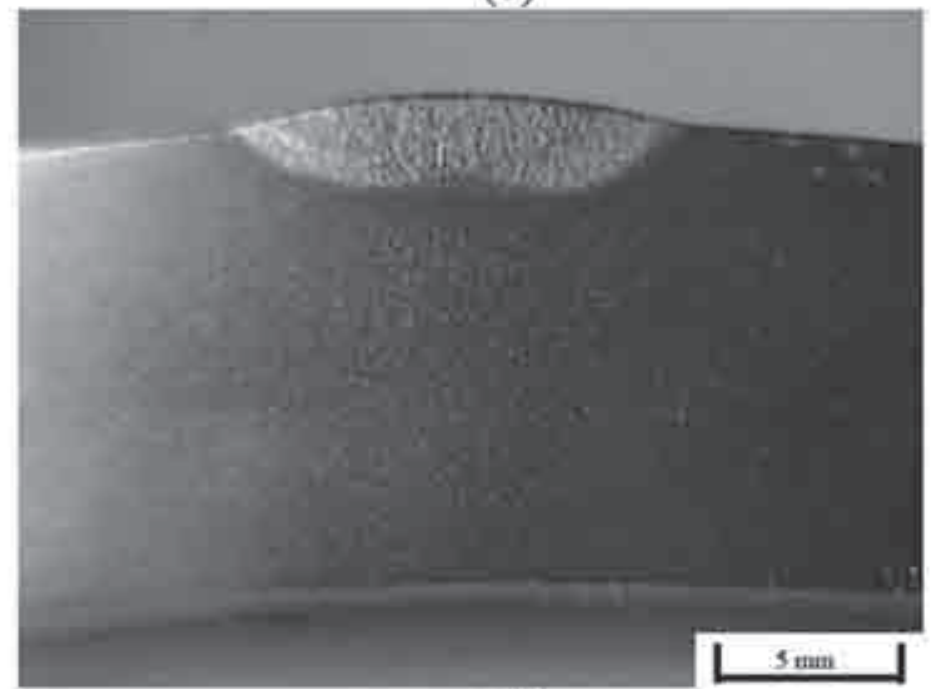

(d)

Figura 4. Macrografias do: cp 1 (a), cp 2 (b), cp 3 (c) e cp 4 (d). Reagente: KOH. 


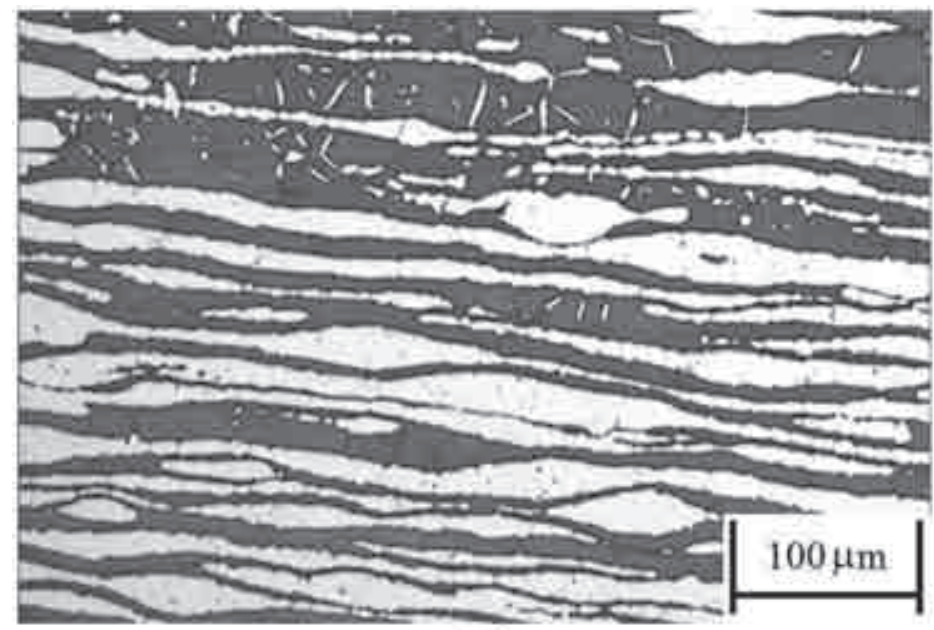

(a)

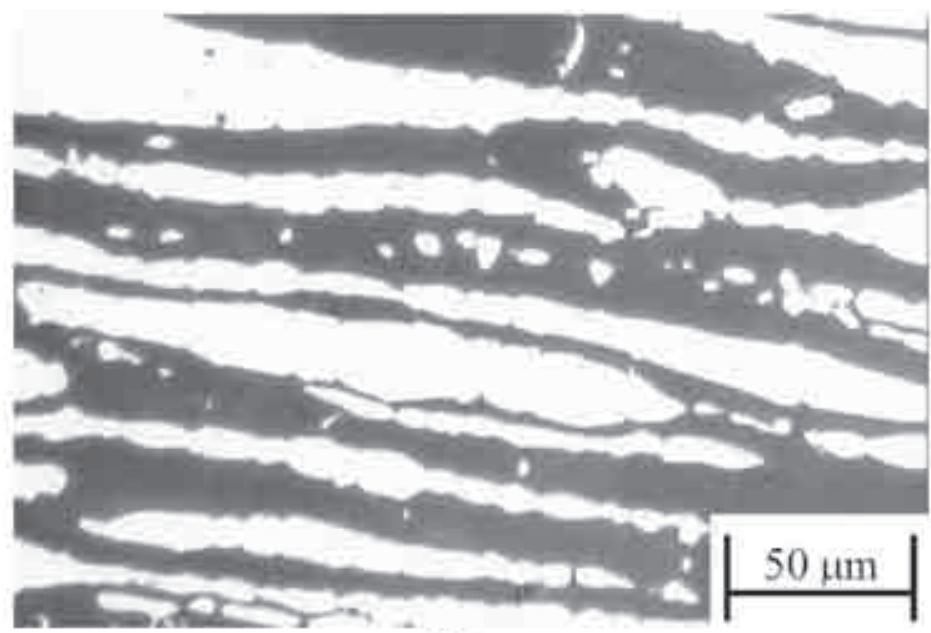

(b)

Figura 5. Microestrutura do MB revelada com o reagente Beraha. g (regiões claras) e d (regiões escuras).

\section{Resultados e Discussão}

$\mathrm{Na}$ figura 4, se observam as macrografias resultantes do cordão de reparo efetuado em cada condição avaliada, sendo possível perceber que as amostras que passaram pelo processo de pré-aquecimento (c) e (d) resultaram em uma maior penetração do metal depositado no corpo-de-prova (cp). Essa observação ficou mais clara nas comparações das soldas realizadas com passe retilíneo (a) e (c). Nas soldas com tecimento oscilante ficou evidenciado o aumento da largura do cordão.

A figura 5 mostra a microestrutura característica do AISD estudado com diferentes aumentos no metal de base (MB). O material está composto de proporções semelhantes das fases austenita (g) (regiões claras) e ferrita (d) (regiões escuras). A quantificação de fases revelou a presença de 50,1 $\pm 2,3 \%$ de ferrita (d). Micrografias obtidas com ataque eletrolítico de $\mathrm{KOH}$, conforme mostrado na tabela 6 , não revelaram a presença de fases deletérias ou terciárias. No entanto, pode ser observada a presença de pequenas frações de austenitas alongadas no interior da matriz ferrítica. A presença destas partículas de austenita pode ser oriunda de um tratamento de solubilização do tubo após fabricação.

Nas microestruturas reveladas da ZTA nas condições 1,2 e 3 , notou-se a presença de austenitas secundárias em forma alongadas do tipo widmanstätten, além de aquelas mais arredondas provavelmente precipitadas a partir de pequenas colônias de nitretos de cromo $\left(\mathrm{Cr}_{2} \mathrm{~N}\right)$ na ferrita, com produto do ciclo térmico imposto durante o processo de soldagem, tal como apresentado na figura 6 para amostra retirada do cp 2. No entanto, não foram detectadas fases intermetálicas (c ou s) nas condições analisadas pela aplicação do reagente de $\mathrm{KOH}$.

A microestrutura daZTA da amostra extraída do cp 4, adjacente ao MS, revelou a provável presença de pequenas fases deletérias precipitadas (fases c e s) preferencialmente nas interfaces dos contornos d/g denotadas pelas zonas mas alaranjadas da figura 7. Este fato está de acordo com o apresentado pela literatura [9], pois nesta condição, um pré-aquecimento do material e passe oscilante, proporcionou uma baixa velocidade de resfriamento,

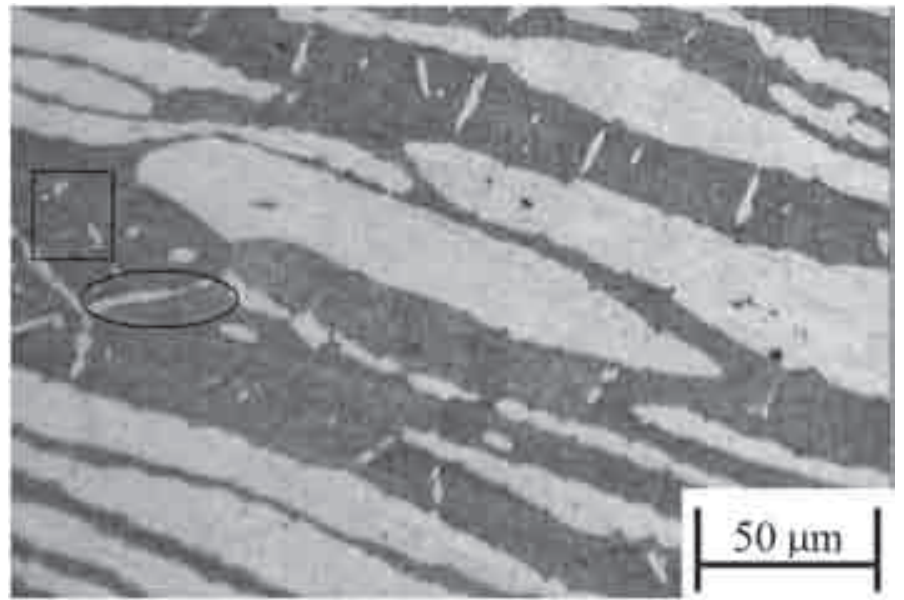

Figura 6. Microestrutura do ZTA da condição 2 revelada com o reagente Beraha. g (regiões claras) e d (regiões escuras).

A região delimitada por um retângulo corresponde a g mais arredondas provavelmente oriundas de $\mathrm{Cr}_{2} \mathrm{~N}$. A zona delimitada por uma elipse corresponde $\mathrm{g}$ do tipo widmanstätten.

se comparado com as demais condições analisadas. O tempo de resfriamento entre $950^{\circ} \mathrm{C} \mathrm{e} 700^{\circ} \mathrm{C}$ calculado para esta condição foi de 138 segundos, conforme informado na tabela 4 que pressupõe a formação de fases deletérias em estágios iniciais. No entanto, deverá ser realizada nesta condição análises por microscopia eletrônica de varredura (MEV) mediante utilização de elétrons retroespalhados (BSE), em amostras sem ataque metalográfico, com o intuito de verificar por espectroscopia por dispersão de energia (EDS) a presença dos distintos compostos deletérios [17].

As micrografias das amostras correspondentes ao metal de solda (MS) dos cps que não tiveram pré-aquecimento são apresentados nas figuras 8 e 9 . Analisando comparativamente, ambas apresentaram diferenças significativas quanto à proporção das fases em relação ao metal base (MB). Neste sentido, foi quantificado $75,4 \pm 1,4 \%$ e $62,8 \pm 1,8 \%$ de ferrita no MS das condições 1 e 2 , respectivamente. Estas diferenças nos valores 


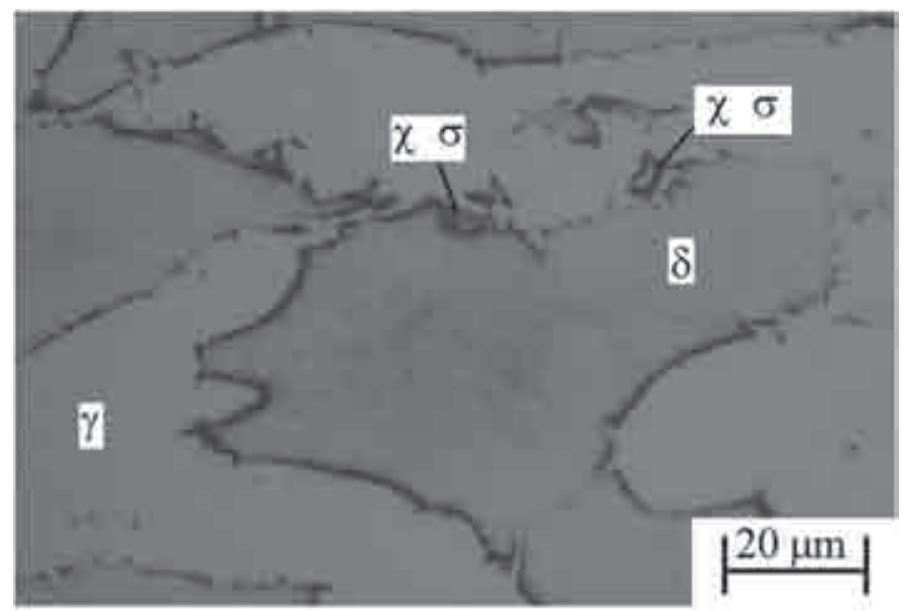

Figura 7. Metalografia da ZTA da amostra extraída do cp 4. Reagente $\mathrm{KOH}$. obtidos são atribuídos ao resfriamento mais lento da condição 2 em relação à 1 como produto do tipo de tecimento, favorecendo assim a uma maior precipitação de austenita na matriz ferrítica e minimizando a formação de nitretos de cromo $\left(\mathrm{Cr}_{2} \mathrm{~N}\right)$. A menor formação de $\mathrm{Cr}_{2} \mathrm{~N}$ é atribuída a que o limite de solubilidade do nitrogênio é muito maior na fase austenita durante o resfriamento entre 1200 e $800^{\circ} \mathrm{C}$ [18]. No entanto, também é interessante lembrar que, pelos motivos já explicados, não foi utilizada mistura gasosa com adição de 1-3\% nitrogênio como gás de proteção, o que poderia favorecer uma maior formação de austenita no metal de solda.

Por outra parte, também podem ser notadas diferenças na morfologia e tamanho das austenitas precipitadas como consequência da diferença na velocidade de resfriamento. No caso da amostra soldada na condição 2 da figura 9, as partículas de austenita são mais grosseiras se comparadas à condição 1 da figura 8, devido à taxa de resfriamento mais lenta.

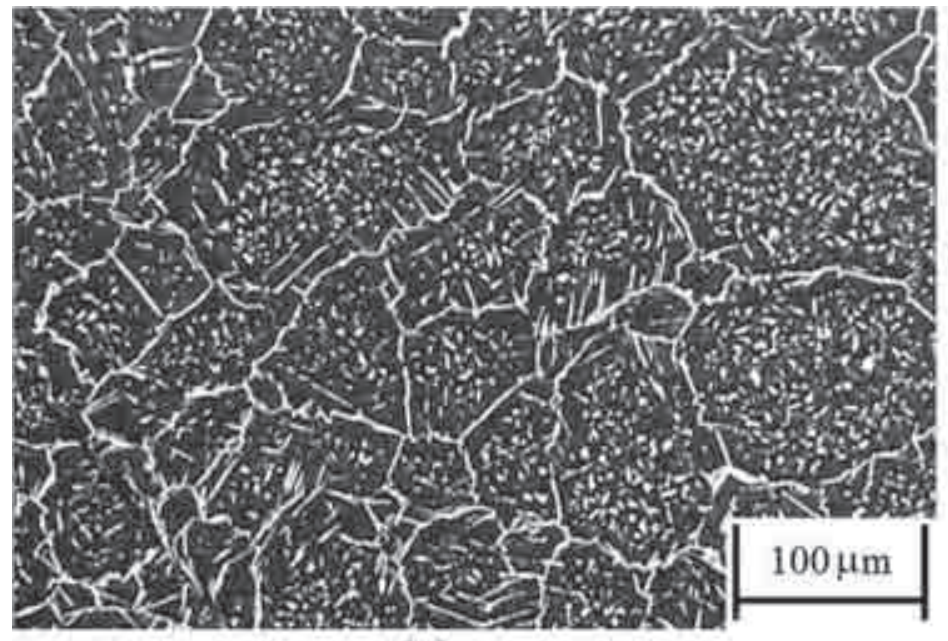

(a)

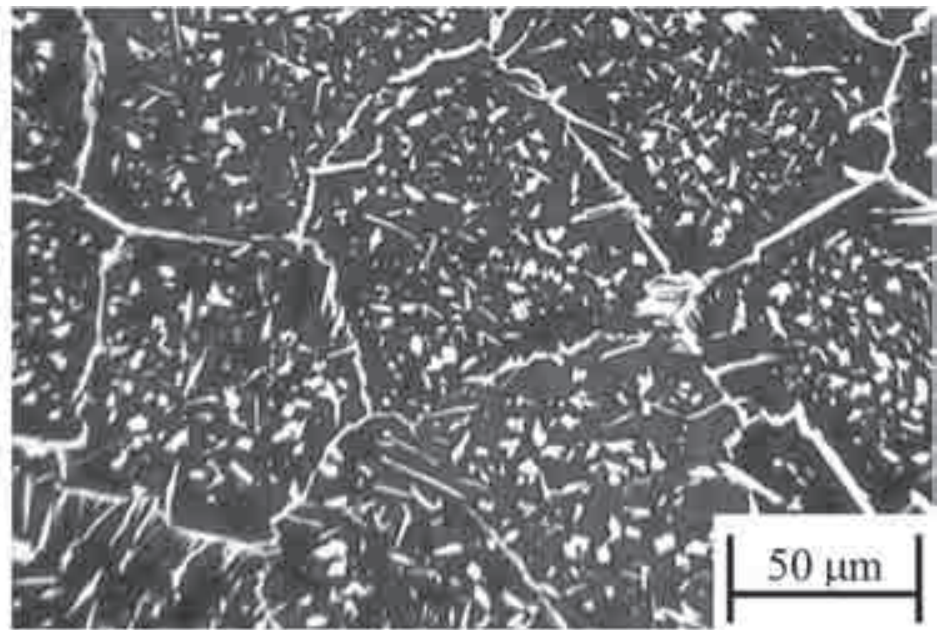

(b)

Figura 8. Microestrutura do MS da amostra extraída do cp 1. g (regiões claras) e d (regiões escuras). Ataque: Beraha.

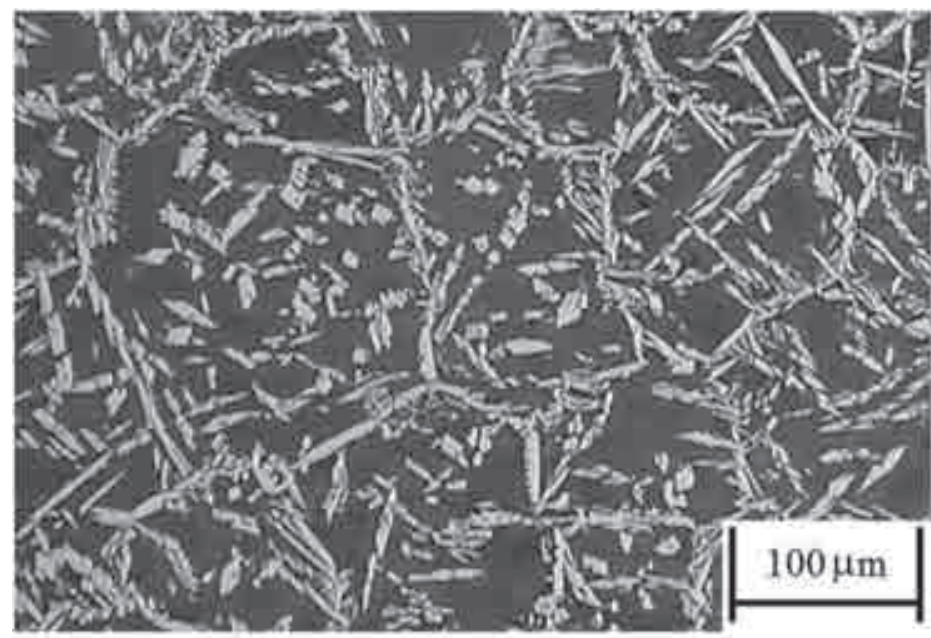

(a)

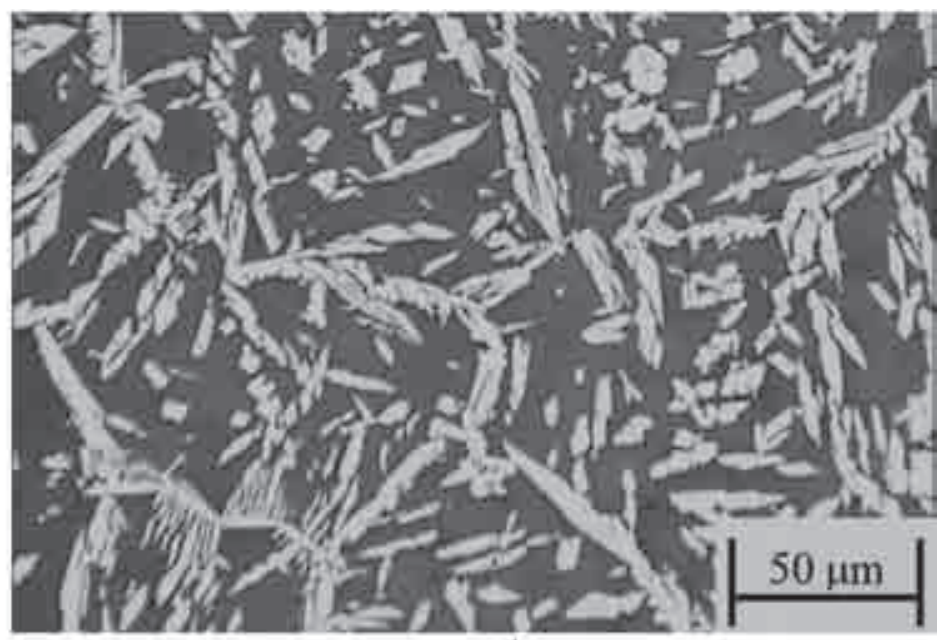

(b)

Figura 9. Microestrutura do MS da amostra extraída do cp 2. g (regiões claras) e d (regiões escuras). Ataque: Beraha. 


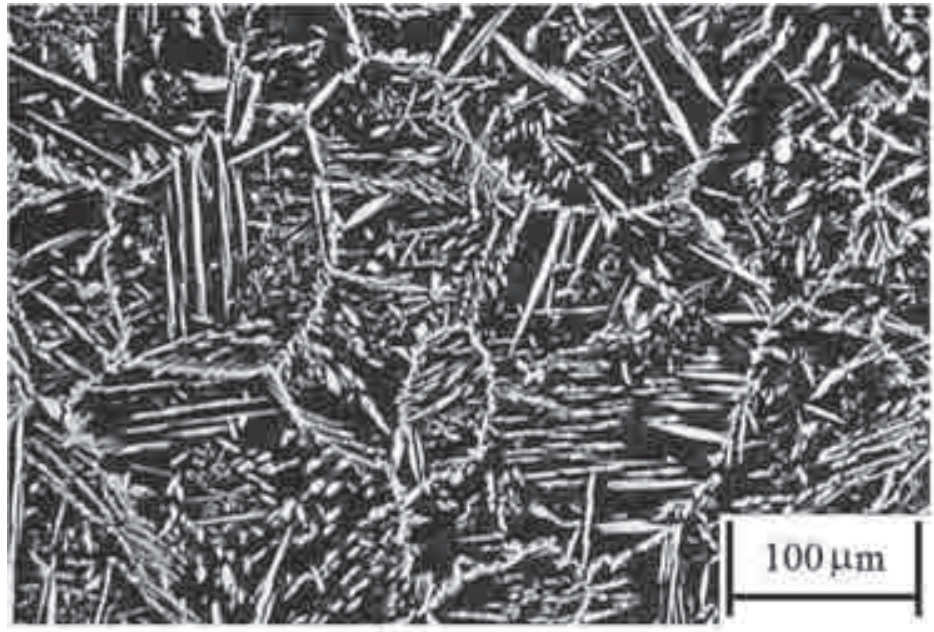

(a)

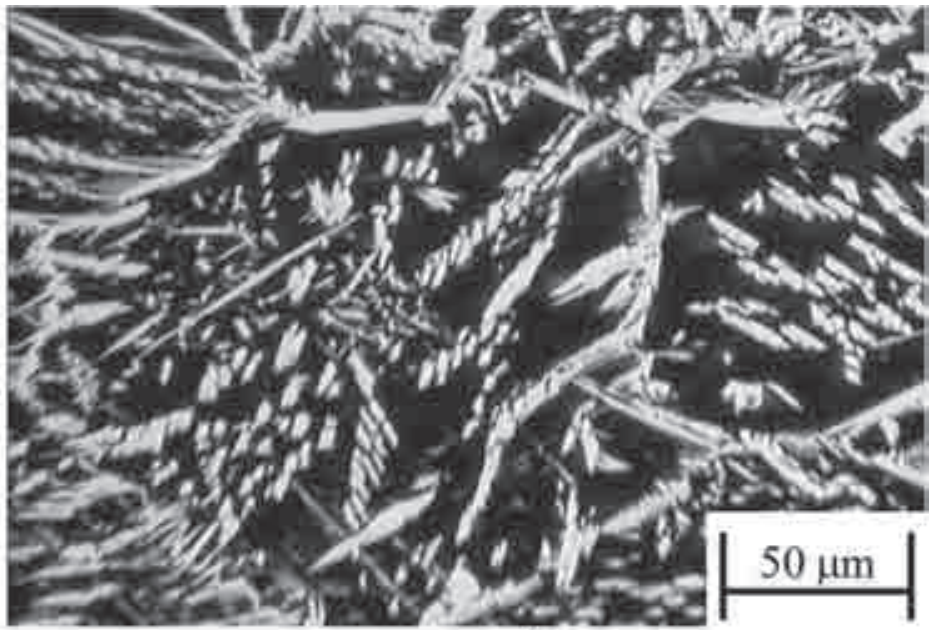

(b)

Figura 10. Microestrutura do MS da amostra extraída do Cp 3. g (regiões claras) e d (regiões escuras). Ataque: Beraha.

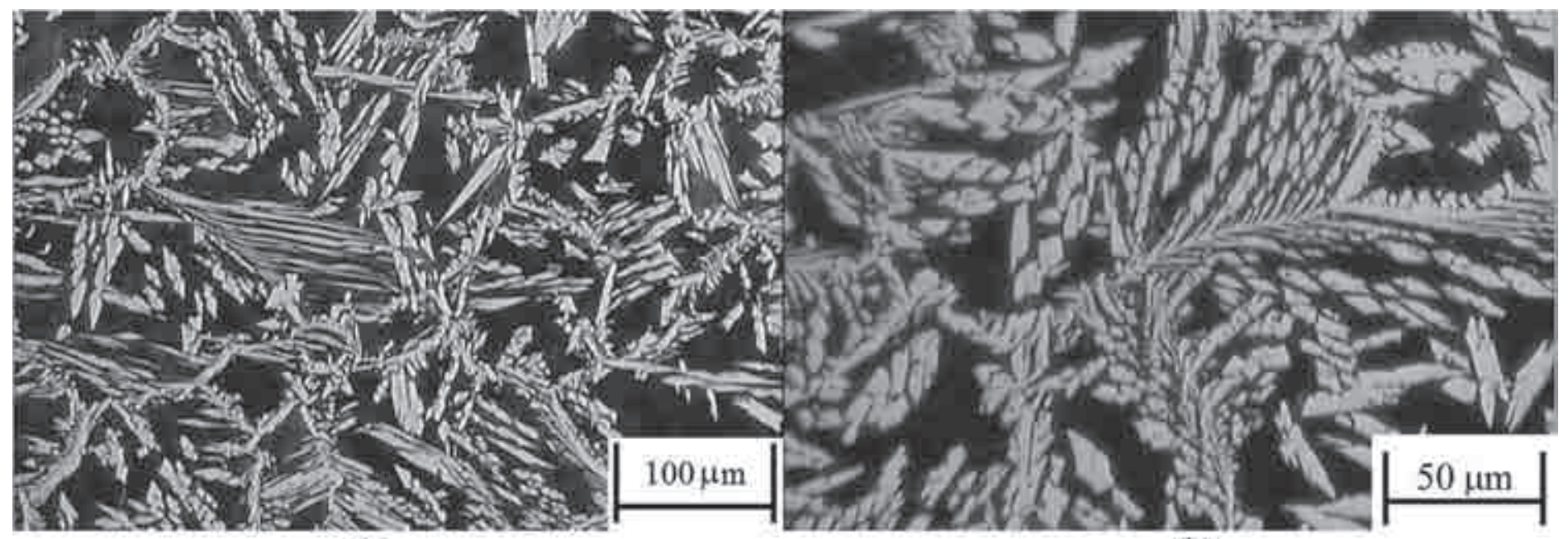

(a)

(b)

Figura 11. Microestrutura do MS da amostra extraída do Cp 4. g (regiões claras) e d (regiões escuras). Ataque: Beraha.

Tabela 7. Percentuais de Ferrita (d) e Austenita (g) nos MS e no MB.

\begin{tabular}{|c|c|c|c|c|c|c|c|c|c|c|}
\hline \multirow{2}{*}{$(\%)$} & \multicolumn{2}{|c|}{ MS 1} & \multicolumn{2}{|c|}{ MS 2} & \multicolumn{2}{|c|}{ MS 3} & \multicolumn{2}{|c|}{ MS 4} & \multicolumn{2}{|c|}{ MB } \\
\hline & $\delta$ & $\gamma$ & $\delta$ & $\gamma$ & $\delta$ & $\gamma$ & $\delta$ & $\gamma$ & $\delta$ & $\gamma$ \\
\hline Média & 75,4 & 24,6 & 62,8 & 37,2 & 59,1 & 40,9 & 59,5 & 40,5 & 50,1 & 49,9 \\
\hline Desvio & \multicolumn{2}{|c|}{1,4} & \multicolumn{2}{|c|}{1,8} & \multicolumn{2}{|c|}{2,0} & \multicolumn{2}{|c|}{1,5} & \multicolumn{2}{|c|}{2,3} \\
\hline
\end{tabular}

No caso das amostras obtidas dos cps 3 e 4 apresentadas nas figuras 10 e 11 , o resfriamento mais lento promoveu uma maior precipitação de austenita no MS se comparada com a condição de soldagem do cp 1 . Os resultados da quantificação apresentados na tabela 7 foram $59,1 \pm 2,0 \%$ e $59,5 \pm 1,5$ de ferrita para os cps 3 e 4, respectivamente. Os valores resultantes da $C P T$ também foram semelhantes às condições do $\mathrm{MB}$, assim como das amostras 1 e 2. Pela aplicação do ataque eletrolítico de $\mathrm{KOH}$, cujas micrografias não foram mostradas neste trabalho, não foi evidenciada a presença de fases deletérias.

Apesar do aporte de calor (H) e do tempo de resfriamento $\left(\mathrm{t}_{\mathrm{T} 1 / \mathrm{T} 2}\right)$ das condições 1 e 3 serem levemente diferentes, a grande diferença na fração de austenita precipitada no metal de solda foi principalmente devido ao pré-aquecimento realizado no cp 3 .

A tabela 8 apresenta os valores de CPT medidos nos metais de solda (MS) e zonas termicamente afetadas (ZTA) das quatro condições analisadas. Segundo Linton et al. [19] a CPT do metal base de aço superduplex se situa na faixa de $80^{\circ} \mathrm{C}$, porém pode ser reduzida à $65^{\circ} \mathrm{C}$ se $1,3 \%$ de fase s estiver presente na microestrutura. Por outro lado, queda semelhante da CPT pode ser encontrada se uma quantidade elevada de nitretos de cromo $\left(\mathrm{Cr}_{2} \mathrm{~N}\right)$ estiver presente. Entretanto, o que se observa é que as CPT's medidas nos metais de solda das quatro condições é muito similar à do metal base, apesar das diferenças de microestrutura. 
Por exemplo, o metal de solda da condição 1 contém uma elevada quantidade de ferrita, o que necessariamente implica em uma elevada quantidade de nitretos de cromo $\left(\mathrm{Cr}_{2} \mathrm{~N}\right)$. Apesar disso, a CPT da condição 1 foi de $72,7^{\circ} \mathrm{C}$, ou seja, no mesmo nível do metal base $\left(72,0^{\circ} \mathrm{C}\right)$ e dos outros metais de solda. Por outro lado, a ZTA da condição 4 , foi de $66,0^{\circ} \mathrm{C}$, refletindo a influência de traços de fases intermetálicas observadas na figura 7. Esta condição, como se sabe, é aquela onde se produziu o resfriamento mais lento entre $950^{\circ} \mathrm{C}$ e $700^{\circ} \mathrm{C}$, não sendo uma condição adequada para o reparo. No outro extremo, com resfriamento extremamente rápido entre $950^{\circ} \mathrm{C}$ e $700^{\circ} \mathrm{C}$, encontra-se a condição 1, cuja ZTA apresentou uma CPT igual a $63{ }^{\circ} \mathrm{C}$. Esta também não é uma condição recomendada, apesar do alto valor da CPT do metal de solda, pois a norma Norsok M601 [20], estabelece um mínimo de 30\% e máximo de 70\% de ferrita (d) para todas as regiões do material após efetuada a solda.

A condição 2 que forneceu um tempo de resfriamento entre $950^{\circ} \mathrm{C}$ e $700^{\circ} \mathrm{C}$ de 28 segundos apresentou os maiores valores de $\mathrm{CPT}$, com $70,0^{\circ} \mathrm{C}$ na ZTA e $74,0^{\circ} \mathrm{C}$ no MS. O tecimento oscilante do cordão foi benéfico pois propiciou um aporte de calor no centro da faixa usualmente recomendada $(0,2-1,5 \mathrm{~kJ} / \mathrm{mm})$ [8]. O teor ligeiramente elevado de ferrita $(62,8 \pm 1,8 \%)$ não implicou em queda de desempenho, mas poderia ser diminuído sensivelmente pelo emprego de misturas gasosas contendo de 1 a $3 \%$ de nitrogênio.

A condição 3, utilizando cordão retilíneo e pré-aquecimento de $400^{\circ} \mathrm{C}$ forneceu bons resultados de CPT e um balanço satisfatório de ferrita e austenita no metal de solda, o que, indiretamente indica uma microestrutura com poucos nitretos de cromo. O pré-aquecimento na soldagem de aços inoxidáveis duplex (AID) e superduplex (AISD) é pouco utilizado, por ser um fator que onera a operação. Quando utilizado, na soldagem de união, o pré-aquecimento, bem como a temperatura interpasse, é limitada à no máximo $150^{\circ} \mathrm{C}$. Os resultados mostram que, para cordões retilíneos, caso em que a região de reparo na prática seja extremamente pequena, a temperatura de pré-aquecimento pode ser mais alta. Ressalta-se, entretanto, que o mais adequando é buscar realizar passes oscilantes, sem pré-aquecimento, tal como na condição de soldagem do cp 2.

Tabela 8. Valores médios da CPT e percentual de ferrita $(\delta)$ obtidos em cada região da solda de reparo.

\begin{tabular}{|c|c|c|c|c|c|c|}
\hline \multirow[b]{2}{*}{ Condição } & \multicolumn{2}{|c|}{ MB } & \multicolumn{2}{|c|}{ MS } & \multicolumn{2}{|c|}{ ZTA } \\
\hline & $\begin{array}{l}\text { CPT } \\
\left({ }^{\circ} \mathbf{C}\right)\end{array}$ & $\begin{array}{c}\delta \\
(\%)\end{array}$ & $\begin{array}{l}\text { CPT } \\
\left({ }^{\circ} \mathrm{C}\right)\end{array}$ & $\begin{array}{c}\delta \\
(\%)\end{array}$ & $\begin{array}{l}\text { CPT } \\
\left({ }^{\circ} \mathrm{C}\right)\end{array}$ & $\begin{array}{c}\delta \\
(\%)\end{array}$ \\
\hline 1 & \multirow{4}{*}{72,0} & \multirow{4}{*}{50,1} & 72,7 & 74,4 & 63,0 & 51,5 \\
\hline 2 & & & 74,0 & 62,8 & 70,0 & 53,9 \\
\hline 3 & & & 71,5 & 59,1 & 67,0 & 54,6 \\
\hline 4 & & & 73,0 & 59,5 & 66,0 & 57,0 \\
\hline
\end{tabular}

\section{4 . Conclusões}

Neste trabalho foram testados quatro procedimentos de reparo por soldagem pelo processo manual GTAW, e os resultados permitem concluir que:

a) A soldagem de reparo, mesmo que realizada com gás de proteção argônio puro, é possível de ser realizada, sem prejuízo considerável à resistência à corrosão por pites do material.

b) Dentre as condições analisadas, a mais adequada foi aquela que forneceu aporte de calor igual a $0,911 \mathrm{~kJ} / \mathrm{mm}$ e tempo de resfriamento entre $950^{\circ} \mathrm{C} \mathrm{e} 700^{\circ} \mathrm{C}$ igual a 28s. Nesta condição obteve-se um teor de ferrita de $62,8 \pm 1,8 \%$ e CPT igual a $70,0^{\circ} \mathrm{C}$ na ZTA e $74,0^{\circ} \mathrm{C}$ no $\mathrm{MS}$, valores muito semelhantes à do $\mathrm{MB}$ $\left(72,0^{\circ} \mathrm{C}\right)$.

c) Para reparos estreitos, a utilização de passes retilíneos pode ser feita com pré-aquecimento para evitar um resfriamento muito rápido do cordão. $\mathrm{O}$ teste realizado com uma temperatura de pré-aquecimento de $400^{\circ} \mathrm{C}$ forneceu uma microestrutura adequada e valores de CPT no MS $\left(71,5^{\circ} \mathrm{C}\right)$ e na ZTA $\left(67,0^{\circ} \mathrm{C}\right)$ próximos do MB.

\section{Agradecimentos}

A CAPES, FAPERJ e CNPq pelo suporte financeiro na realização deste trabalho.

\section{Referências Bibliográficas}

[1] REICK, W.; POHL, M.; PADILHA, A.F. O desenvolvimento dos aços inoxidáveis ferríticos-austeníticos com microestrutura duplex. In: CONGRESSO ANUAL DA ASSOCIAÇÃO BRASILEIRA DE METALURGIA E MATERIAIS, 47. 1992, Belo Horizonte. Anais. Belo Horizonte: ABM, 1992. Vol 48, No409.

[2] MUTHUPANDI, V.; BALA SRINIVASAN, P.; SESHADRI, S.K., SUNDARESAN S. Effect of Weld Metal Chemistry and Heat Input on the Structure and Properties of Duplex Stainless Steel Welds. Materials Science and Engineering. Vol. A358 (2003). 9-16, 2003.

[3] GUNN, R.N. Duplex stainless steels. Microstructure, properties and applications. Cambridge - England: Abington Publishing, 2003. 204 p.

[4] LOPEZ, N.; CID, M.; PUIGGALI, M. Influence of s-Phase on Mechanical Properties and Corrosion Resistance of Duplex Stainless Steels. Corrosion Science. Vol. 41 (1999). 1615-1631, 1999.

[5] TAVARES, S.S.M.; DA SILVA, M.R.; NETO, J.M. Magnetic Property Changes During Embrittlement of a Duplex Stainless Steel. Journal of Alloys and Compounds. Vol. 313 (2000). 168173, 2000.

[6] RAMIREZ LONDOÑO, A.J. Estudo da precipitação de nitreto de cromo e fase sigma por simulação térmica da zona afetada pelo calor na soldagem multipasse de aços inoxidáveis duplex. Dissertação de mestrado, Escola Politécnica da Universidade de São Paulo, 1997.

[7] NILSSON, J.O. Overview Super duplex stainless steels. Materials Science and Technology, Vol. 8. 685-700, 1992. 
[8] PARDAL, J.M.; TAVARES, S.S.M.; FARIA, R.A. Aços inoxidáveis Duplex (austeno-ferríticos) microestrutura e propriedades. Metalurgia \& Materiais. 2008; 64: 624-626.

[9] BUTTING. Processing duplex/superduplex. Butting Germany. Catálogo de produtos. Disponível em: < www. butting.de/fileadmin/Redakteure/.../BUTTING Brasilien port. pdf >. Acesso em: 07 Out. 2010.

[10] OUTOKUMPU, Steel Grades, Properties and Global Standard. Disponível em: < http://www.outokumpu.com/pages/ Page $\quad 6522 . a s p x>$. Acesso em: 07 Out. 2010.

[11] ASM HANDBOOK Volume 06. Welding, Brazing and Soldering. ASM International, 2003. CD-ROM. p. 2873.

[12] ASM HANDBOOK Volume 09. Metallography and microstructures. ASM International, 2004. CD-ROM. p. 2733.

[13] DOMÍNGUEZ-AGUILAR, M.A.; NEWMAN, R.C. Detection of Deleterious Phases in Duplex Stainless Steel by Weak Galvanostatic Polarization in Alkaline Solution. Corrosion Science. Vol. 48 (2006). 2560-2576, 2006.

[14] PARK, C.-J.; KWON, H.-S.; LOHRENGEL, M.M. Microelectrochemical Polarization Study on 25\% Cr Duplex Stainless Steel. Materials Science and Engineering. Vol. A372 (2004). 180-185, 2004.

[15] IMAGE TOOL Version 3.0. Department of Dental Diagnostic Science at The University of Texas Health Science Center (UTHSCSA), San Antonio, Texas. Disponível em: < http://ddsdx.uthscsa.edu/dig/itdesc.html >. Acesso em: 07 Out. 2010.

[16] ASTM G150-99: Standard Test Method for Electrochemical Critical Pitting Temperature Testing of Stainless Steels.

[17] PARDAL, J.M.; TAVARES, S.S.M.; CINDRA FONSECA, M.P.; SOUZA, J.A.; VIEIRA, L.M.; ABREU, H.F.G. Deleterious Phases Precipitation on Superduplex Stainless Steel UNS S32750: Characterization by Light Optical and Scanning Electron Microscopy. Materials Research. Vol. 13 (3) (2010). 401-407, 2010.

[18] LIPPOLD, J.C.; KOTECKI, D.J. Welding metallurgy and weldability of stainless steels. John Wiley \& Sons, Inc, 2005.

[19] LINTON, V.M.; LAYCOCK, N.J.; THOMSEN, S.J.; KLUMPERS, A. Failure of a Super Duplex Stainless Steel Reaction Vessel. Engineering Failure Analysis. Vol. 11 (2004). 243-256, 2004.

[20] NORSOK STANDARD M-601: Welding and Inspection of Piping. Rev. 4, July 2004 